University of Nebraska - Lincoln

DigitalCommons@University of Nebraska - Lincoln

U.S. Environmental Protection Agency Papers

U.S. Environmental Protection Agency

2008

\title{
Acute respiratory health effects of air pollution on children with asthma in US inner cities
}

\author{
George T. O'Connor \\ Boston University School of Medicine \\ Lucas Neas \\ US Environmental Protection Agency \\ Benjamin Vaughn \\ Rho Federal Systems Division, Inc, Chapel Hill \\ Meyer Kattan \\ Mount Sinai School of Medicine, New York \\ Herman Mitchell \\ US Environmental Protection Agency \\ See next page for additional authors
}

Follow this and additional works at: https://digitalcommons.unl.edu/usepapapers

Part of the Civil and Environmental Engineering Commons

O'Connor, George T.; Neas, Lucas; Vaughn, Benjamin; Kattan, Meyer; Mitchell, Herman; Crain, Ellen F.; Evans, III, Richard; Gruchalla, Rebecca; Morgan, Wayne; Stout, James; Adams, G. Kenneth; and Lippmann, Morton, "Acute respiratory health effects of air pollution on children with asthma in US inner cities" (2008).

U.S. Environmental Protection Agency Papers. 12.

https://digitalcommons.unl.edu/usepapapers/12

This Article is brought to you for free and open access by the U.S. Environmental Protection Agency at DigitalCommons@University of Nebraska - Lincoln. It has been accepted for inclusion in U.S. Environmental Protection Agency Papers by an authorized administrator of DigitalCommons@University of Nebraska - Lincoln. 


\section{Authors}

George T. O'Connor; Lucas Neas; Benjamin Vaughn; Meyer Kattan; Herman Mitchell; Ellen F. Crain; Richard Evans, III; Rebecca Gruchalla; Wayne Morgan; James Stout; G. Kenneth Adams; and Morton Lippmann 


\title{
Acute respiratory health effects of air pollution on children with asthma in US inner cities
}

\author{
George T. O'Connor, MD, MS, ${ }^{a}$ Lucas Neas, DSc, ${ }^{b}$ Benjamin Vaughn, MS, ${ }^{c}$ Meyer Kattan, MD, ${ }^{d}$ Herman Mitchell, PhD, ${ }^{b}$ \\ Ellen F. Crain, MD, ${ }^{e}$ Richard Evans III, MD, ${ }^{f} \dagger$ Rebecca Gruchalla, MD, PhD, ${ }^{g}$ Wayne Morgan, MD, ${ }^{\text {h }}$ James Stout, MD, \\ G. Kenneth Adams, MD, ${ }^{\mathbf{j} *}$ and Morton Lippmann, PhD $^{\mathbf{k}} \quad$ Boston, Mass, Research Triangle Park and Chapel Hill, NC, New York, \\ Bronx, and Tuxedo, NY, Chicago, Ill, Dallas, Tex, Tucson, Ariz, Seattle, Wash, and Bethesda, Md
}

Background: Children with asthma in inner-city communities may be particularly vulnerable to adverse effects of air pollution because of their airways disease and exposure to relatively high levels of motor vehicle emissions.

Objective: To investigate the association between fluctuations in outdoor air pollution and asthma morbidity among inner-city children with asthma.

Methods: We analyzed data from 861 children with persistent asthma in 7 US urban communities who performed 2-week periods of twice-daily pulmonary function testing every 6 months for 2 years. Asthma symptom data were collected every 2 months. Daily pollution measurements were obtained from the Aerometric Information Retrieval System. The relationship of lung function and symptoms to fluctuations in pollutant concentrations was examined by using mixed models.

Results: Almost all pollutant concentrations measured were below the National Ambient Air Quality Standards. In singlepollutant models, higher 5-day average concentrations of $\mathrm{NO}_{2}$, sulfur dioxide, and particles smaller than $2.5 \mu \mathrm{m}$ were associated with significantly lower pulmonary function. Higher pollutant levels were independently associated with reduced lung function in a 3-pollutant model. Higher concentrations of $\mathrm{NO}_{2}$ and particles smaller than $2.5 \mu \mathrm{m}$ were associated with asthma-related missed school days, and higher $\mathrm{NO}_{2}$ concentrations were associated with asthma symptoms. Conclusion: Among inner-city children with asthma, short-term increases in air pollutant concentrations below the National Ambient Air Quality Standards were associated with adverse respiratory health effects. The associations with $\mathrm{NO}_{2}$ suggest that motor vehicle emissions may be causing excess morbidity in this population. (J Allergy Clin Immunol 2008;121:1133-9.)

Key words: Nitrogen dioxide, ozone, sulfur dioxide, carbon monoxide, fine particle emissions, asthma in children

The short-term respiratory health effects of outdoor air pollutants at levels currently found in the United States remain uncertain. Time-series analyses have revealed increased cardiopulmonary mortality and hospitalizations after days with elevated particulate matter (PM) air pollution, ${ }^{1-4}$ as well as increased asthma-related emergency visits and hospitalizations after days with high pollution levels. ${ }^{5-7}$ Some authors, however, have stressed the importance of confirming the results of ecologic analyses with studies using individual-level data. ${ }^{8}$

Panel studies of healthy children ${ }^{9-11}$ or children with asthma ${ }^{12-19}$ have revealed short-term increases in respiratory symptoms and decreases in lung function after exposure to higher levels of $\mathrm{PM}^{20}$ and/ or $\mathrm{O}_{3}$. Most studies have been limited to fairly small samples of subjects and a single-season. Few published panel studies ${ }^{10,14,21-}$ ${ }^{24}$ have examined the effects of PM with aerodynamic diameter less than $2.5 \mu \mathrm{m}$ (PM2.5), a pollutant that penetrates to distal bronchioles and is strongly associated with mortality in population studies. $^{1,2,4,25}$ Studies on relatively small numbers of patients with asthma have suggested an adverse effect of PM2.5 on peak expiratory flow rate (PEFR) and symptoms. ${ }^{19}$ A panel study of 58 children with asthma in Seattle revealed that increases in PM2.5 and PM with aerodynamic diameter less than $10 \mu \mathrm{m}$ (PM10), as well

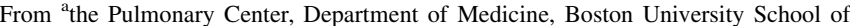
Medicine; ${ }^{\mathrm{b}}$ the US Environmental Protection Agency, Research Triangle Park; ${ }^{\mathrm{c}}$ Rho Federal Systems Division, Inc, Chapel Hill; ${ }^{d}$ the Department of Pediatrics, Mount Sinai School of Medicine, New York; ${ }^{e}$ the Department of Pediatrics (Emergency Medicine), Albert Einstein College of Medicine/Jacobi Medical Center, Bronx; ${ }^{\mathrm{f}}$ the Departments of Pediatrics and Medicine, Northwestern University Medical School, Chicago; ${ }^{g}$ the Departments of Medicine and Pediatrics, University of Texas Southwestern Medical Center at Dallas; ${ }^{\mathrm{h}}$ the Respiratory Sciences Center, University of Arizona College of Medicine; ${ }^{i}$ the Department of Pediatrics, University of Washington School of Medicine; ${ }^{j}$ the National Institute of Allergy and Infectious Diseases, Bethesda; and ${ }^{\mathrm{k}}$ the Department of Environmental Medicine, New York University School of Medicine, Tuxedo.

*Retired.

$\dagger$ Deceased.

Supported by grants AI-39769, AI-39900, AI-39902, AI-39789, AI-39901, AI-39761, AI-39785, and AI-39776 from the National Institute of Allergy and Infectious Diseases and the National Institute of Environmental Health Sciences, National Institutes of Health, Department of Health and Human Services; and by grant M01 RR00533 from the National Center for Research Resources, National Institutes of Health, Department of Health and Human Services; with partial support provided by the US Environmental Protection Agency through an interagency agreement with the
National Institute of Allergy and Infectious Diseases. The manuscript has been subjected to agency review and approved for publication. The opinions expressed here do not necessarily reflect US Environmental Protection Agency policy. Mention of trade names or commercial products does not constitute endorsement or recommendation for use.

Disclosure of potential conflict of interest: R. Gruchalla has received research support from Novartis. W. Morgan has consulting arrangements with the Cystic Fibrosis Foundation; has patent licensing arrangements with the Childhood Asthma Research and Education Network and the National Heart, Lung, and Blood Institute; has received research support from the Cystic Fibrosis Foundation and the National Institute of Allergy and Infectious Diseases; and is on the advisory board for Genentech. The rest of the authors have declared that they have no conflict of interest.

Received for publication August 22, 2007; revised February 11, 2008; accepted for publication February 11, 2008.

Available online April 14, 2008.

Reprint requests: George T. O'Connor, MD, MS, Boston University School of Medicine, Pulmonary Center, 715 Albany St, Room 304, Boston, MA 02118. E-mail: goconnor@ bu.edu.

0091-6749

doi:10.1016/j.jaci.2008.02.020 


\section{Abbreviations used \\ ICAS: Inner-City Asthma Study}

NAAQS: National Ambient Air Quality Standards

PEFR: Peak expiratory flow rate

PM: Particulate matter

PM10: Particulate matter with aerodynamic diameter of less than $10 \mu \mathrm{m}$

PM2.5: Particulate matter with aerodynamic diameter of less than $2.5 \mu \mathrm{m}$

as increases in $\mathrm{CO}$, a surrogate for motor vehicle emissions, were associated with an increased risk of severe asthma attacks and medication use. $^{26}$

Children with asthma living in poor urban neighborhoods are particularly vulnerable to the adverse effects of air pollution because of their underlying airways disease and their residence in communities with relatively high levels of motor vehicle emissions. ${ }^{27}$ Previous panel studies focusing on urban children with asthma ${ }^{19,21,28}$ have suggested effects of air pollution on symptoms, but effects on PEFR have not been consistent, and previous studies did not include measurements of $\mathrm{FEV}_{1}$. The substantial economic implications of compliance with ambient air quality standards require more precise estimates of the health effects of air pollution in this population.

The Inner-City Asthma Study (ICAS) ${ }^{29,30}$ evaluated the effectiveness of a multifaceted, home-based, environmental intervention for inner-city children with asthma. Using data collected for this study, we analyzed the relationship between short-term fluctuations in outdoor air pollutant concentrations and changes in pulmonary function and respiratory symptoms among children with asthma in 7 US inner-city communities. Although the respiratory health of children with asthma may be affected by outdoor pollution, indoor pollution, and indoor exposure to pollution from outdoor sources, this study focuses on ambient pollution concentrations as measured outdoors, currently the only pollution concentrations regulated by federal law. The data were collected between August 1998 and July 2001, reflecting current ambient pollutant concentrations.

\section{METHODS}

Additional detail on methods is provided in this article's Online Repository at www.jacionline.org.

\section{Sample}

The ICAS cohort included 937 children with persistent asthma and atopy (1 or more positive allergy skin tests to common indoor allergens) who were 5 to 12 years old and lived in low-income census tracts in Boston, the Bronx, Chicago, Dallas, New York, Seattle, and Tucson. Subject recruitment took place throughout a full 12-month period, such that the monitoring of health and pollution data, as described, was staggered throughout the calendar year. We excluded 53 children living in the Tacoma area near Seattle because of a lack of nearby pollution monitoring stations with sufficient data and 23 children from other sites who had insufficient pulmonary function data, leaving 861 children for analysis.

\section{Health data}

Every 6 months for 2 years, children performed twice-daily spirometry for 2 weeks by using an electronic spirometer that recorded the date and time of measurements. Percent predicted values were calculated by using published regression equations. ${ }^{31}$ Asthma symptom data were collected by telephone interview every 2 months. Caretakers were asked to recall the number of days in the past 2 weeks that the child experienced specific asthma symptoms or missed school because of asthma.

\section{Pollution measurements}

Daily measurements of the outdoor concentrations of PM2.5, $\mathrm{NO}_{2}, \mathrm{SO}_{2}$, $\mathrm{CO}$, and $\mathrm{O}_{3}$ (average of hourly measurements) were obtained from the US Environmental Protection Agency Aerometric Information Retrieval System database. ${ }^{32}$ Within each community, we used data from all available monitoring sites that were located in reasonable proximity to the homes of the study population, that had reasonably complete pollution data during the study period, and that were not located at an industrial pollution source that would make measurements meaningless in terms of community exposure. In most cases, subjects' homes were fairly tightly clustered; the median distance to the nearest monitoring station was $2.3 \mathrm{~km}$. For each monitoring site, we used all available pollution data; if more than 1 monitoring site within a city was used, their readings were combined using the method of Zanobetti et al. ${ }^{33}$

\section{Data analysis}

The relationships between lung function and pollutant concentrations were assessed by using mixed-effects models, in which each day's FEV Fr PEFR (percentage of predicted) was the dependent variable, and the independent variables included pollutant concentrations (the mean of the 1 or more days preceding the day of the pulmonary function measurement), city, month, a city-by-month interaction term, the mean temperature on the day of the pulmonary function measurement, whether it was obtained in the morning or evening, and the ICAS intervention group. This mixed modeling approach assesses variation of health outcomes with pollution level both within individuals and between individuals. The models let individuals have their own individual intercept of the outcome-exposure relationship, thereby adjusting for differences in the baseline lung function of individuals. Similar to other time-series investigations of acute air pollution health effects, we examined alternative pollution concentration moving averages from 1 to 7 days. The 5 -day moving average pollution concentration provided the most consistent significant associations with lung function effects, and we therefore used 5day averages for the main analyses presented.

Single-pollutant models were used to examine the relationship of lung function to 1 pollutant at a time. A 3-pollutant model including $\mathrm{NO}_{2}, \mathrm{O}_{3}$, and PM2.5 was used to evaluate the independent relationship of lung function to the concentration of each of these pollutants while adjusting for the associations with the other 2 pollutants.

The relationship of 2-week recall symptoms to pollutant measurements were assessed by using generalized estimating equation models. The frequency of each symptom or the occurrence of 1 or more school absence during the recall period was the dependent variable, and the independent pollution variable was the mean concentration during the 19 days preceding the interview-that is, the 14 days of the symptom recall period plus a 5-day lag period preceding the symptom recall period. The other independent variables were the same as in the lung function models.

For all models, results are presented by contrasting symptoms or lung function at the 90th percentile of all measurements of a given pollutant to symptoms or lung function at the 10th percentile of measurements.

\section{RESULTS}

The 861 children had a mean age of 7.7 years and were mostly black or Hispanic (Table I). At entry, only $11.5 \%$ were taking inhaled corticosteroids, and nearly half lived with a cigarette smoker. We retrieved 3299 two-week periods of pulmonary function data from the 861 children - that is, $70.4 \%$ of the maximum possible - and 10,056 telephone interviews - that is, $89.4 \%$ of the maximum possible.

Across all communities, there were 5053 observation days with data for all 5 pollutants. There was a substantial correlation, after adjustment for community and month, among the daily 
TABLE I. Characteristics of 861 children with asthma included in the analysis

\begin{tabular}{lc}
\hline Characteristic & $\begin{array}{c}\text { Mean (SD) or } \\
\text { percentage }\end{array}$ \\
\hline Age (y) & $7.67(2.00)$ \\
Male sex & $62.1 \%$ \\
Race/ethnicity & \\
$\quad$ Black & $39.7 \%$ \\
Hispanic & $42.9 \%$ \\
Non-Hispanic white & $5.7 \%$ \\
Other & $11.7 \%$ \\
Using inhaled corticosteroid on study entry & $11.5 \%$ \\
One or more cigarette smokers at home & $47.4 \%$ \\
Low birth weight & $12.8 \%$ \\
Baseline \% predicted premed FEV & $85.5(22.4)$ \\
Baseline \% predicted premed PEF & $73.5(21.9)$ \\
\hline Morbidity outcomes over a period of & Mean symptom days \\
2 years of follow-up & per 2 weeks (SD) \\
\hline Days with wheeze, tightness in chest, cough & $2.9(3.75)$ \\
Nights child woke up because of asthma & $1.7(2.76)$ \\
Days child slowed down or stopped play & $2.2(3.20)$ \\
No. of school days missed & $0.8(1.62)$ \\
\hline
\end{tabular}

concentrations, with only PM2.5 and $\mathrm{O}_{3}$ uncorrelated (Table II). $\mathrm{PM} 2.5$ and $\mathrm{SO}_{2}$ concentrations were well below the 24-hour average National Ambient Air Quality Standards (NAAQS), and 24hour $\mathrm{NO}_{2}$ concentrations were below the annual NAAQS (Fig 1). Maximum 8-hour average $\mathrm{CO}$ concentrations were well below the NAAQS, and only $1 \%$ to $2 \%$ of the maximum 8 -hour average $\mathrm{O}_{3}$ concentrations exceeded the NAAQS, which allows 3 exceedances per year.

In single-pollutant models, the $\mathrm{FEV}_{1}$ and PEFR were significantly related to the 5-day average $\mathrm{PM} 2.5, \mathrm{SO}_{2}$, and $\mathrm{NO}_{2}$, but not to the 1-day average concentration (Fig 2). For $\mathrm{O}_{3}$, effect estimates from models with 1-day or 5-day average concentrations did not differ. For PM2.5, $\mathrm{SO}_{2}$, and $\mathrm{NO}_{2}, 5$-day average concentrations at the 90th percentile were associated with significantly lower $\mathrm{FEV}_{1}$ and PEFR compared with concentrations at the 10th percentile (Table III). For $\mathrm{O}_{3}$ and $\mathrm{CO}$, associations with $\mathrm{FEV}_{1}$ and PEFR were smaller and not statistically significant. For each pollutant, we also created models to examine whether the 5-day average pollutant concentration was related to the risk of experiencing a percent-predicted $\mathrm{FEV}_{1}$ and PEFR more than $10 \%$ below personal best (defined as the 95th percentile of all $\mathrm{FEV}_{1}$ or PEFR measurements for that individual). The risk of a experiencing a percent-predicted $\mathrm{FEV}_{1}$ more than $10 \%$ below personal best was significantly related to the 5-day average concentrations of $\mathrm{NO}_{2}$ (odds ratio associated with an increment from the 10th to the 90th percentile of pollutant concentration, 1.17; 95\% CI, 1.01, 1.37) and PM2.5 (odds ratio, 1.14; 95\% CI, $1.01,1.29)$. The risk of a experiencing a percent-predicted PEFR more than $10 \%$ below personal best was significantly related to 5-day average $\mathrm{NO}_{2}$ (odds ratio, 1.23; 95\% CI, 1.05, 1.44), PM2.5 (odds ratio, 1.18; 95\% CI, 1.03, 1.35), and $\mathrm{SO}_{2}$ (odds ratio, 1.32; 95\% CI, 1.02, 1.73).

In the 3-pollutant model including $\mathrm{NO}_{2}, \mathrm{O}_{3}$, and $\mathrm{PM} 2.5$ as predictors of $\mathrm{FEV}_{1}$, higher 5-day average $\mathrm{NO}_{2}$ and PM2.5 concentrations were independently associated with significantly lower in $\mathrm{FEV}_{1}$ (Table III). An association between $\mathrm{O}_{3}$ and $\mathrm{FEV}_{1}$ was of similar magnitude but not statistically significant. In the
TABLE II. Correlations between daily pollutant concentrations, adjusted for community and month

\begin{tabular}{lrrrrr}
\hline Pollutant & PM2.5 & Ozone & $\mathbf{N O}_{2}$ & \multicolumn{1}{c}{$\mathbf{c O}$} & $\mathbf{S O}_{\mathbf{2}}$ \\
\hline $\mathrm{PM} 2.5$ & 1.00 & -0.02 & 0.59 & 0.44 & 0.37 \\
Ozone & & 1.00 & -0.31 & -0.38 & -0.43 \\
$\mathrm{NO}_{2}$ & & & 1.00 & 0.54 & 0.59 \\
$\mathrm{CO}$ & & & 1.00 & 0.32 \\
$\mathrm{SO}_{2}$ & & & & & 1.00 \\
\hline
\end{tabular}

3-pollutant model for PEFR, higher 5-day average $\mathrm{NO}_{2}$ and $\mathrm{O}_{3}$ concentrations were independently associated with significantly lower PEFR (Table III). Lung function models including all 5 pollutants revealed, as expected, that relationships to individual pollutants were diluted compared with those seen in 3-pollutant models; however, $\mathrm{NO}_{2}$ remained a significant predictor of $\mathrm{FEV}_{1}$, and $\mathrm{NO}_{2}$ and $\mathrm{O}_{3}$ remained significant predictors of PEFR in these 5-pollutant models (results not shown).

For asthma-related symptoms and school absences during the 2-week recall periods, single-pollutant models revealed significant or nearly significant positive associations between higher $\mathrm{NO}_{2}$ concentrations and each of the health outcomes (Table IV). Significant positive associations with symptoms but not school absence were observed in the single-pollutant model for $\mathrm{CO}$. The $\mathrm{O}_{3}, \mathrm{PM} 2.5$, and $\mathrm{SO}_{2}$ concentration did not appear significantly associated with symptoms or school absence except for a significant association between PM2.5 and school absence. In the 3-pollutant model that included $\mathrm{NO}_{2}, \mathrm{O}_{3}$, and PM2.5 (Table IV), the $\mathrm{NO}_{2}$ concentration remained significantly or nearly significantly associated with each of the symptoms, although the association with missed school days was attenuated and no longer statistically significant. The $\mathrm{O}_{3}$ and PM2.5 concentrations were not significantly associated with symptoms or school absences in the 3-pollutant models. In symptom models including all 5 pollutants, the associations for $\mathrm{NO}_{2}$ were slightly attenuated and no longer statistically significant, with the associations divided between $\mathrm{NO}_{2}$ and $\mathrm{CO}$ terms in the model (results not shown).

We performed analyses in which interaction terms were added to models to look for potential modification of air pollution effects by various subject characteristics. These analyses revealed no consistent pattern of effect modification by the use of inhaled corticosteroid, the presence of a cigarette smoker in the home, more severe asthma (defined by a composite index based on use of inhaled corticosteroid, symptom frequency in the past 2 weeks, and unscheduled health care utilization in the past 2 months), or ICAS study group (intervention versus control).

\section{DISCUSSION}

We observed significant associations between pollutant exposures and respiratory health outcomes in a large sample of children with asthma in 7 urban US communities, despite the fact that the daily pollutant concentrations were almost all below the current NAAQS. Higher concentrations of $\mathrm{NO}_{2}, \mathrm{PM} 2.5$, and $\mathrm{SO}_{2}$ were associated with decrements in pulmonary function, and higher $\mathrm{NO}_{2}$ concentrations were also associated with more frequent asthma symptoms and asthma-related school absences. We observed associations between 5-day average pollutant concentrations and lung function decrements that were not seen for single-day average concentrations, suggesting that some of the 


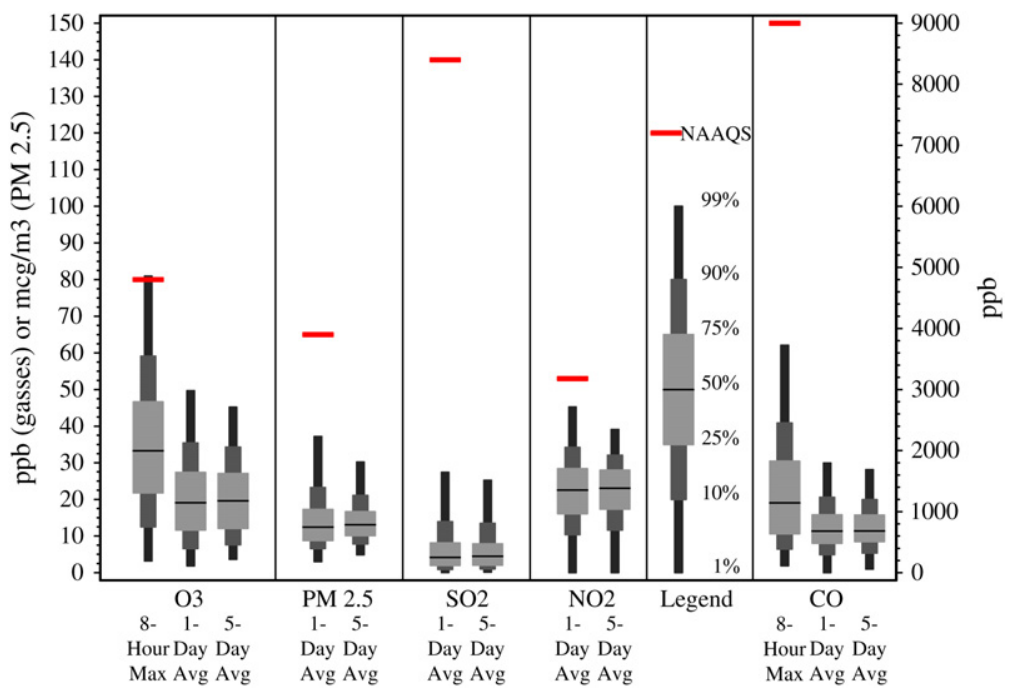

FIG 1. Box plots showing the distribution of the ambient air pollutant concentrations measured in all 7 communities during the 2-year period of the study. The bars indicate the 1st, 10th, 25th, 50th, 75th, 90th, and 99th percentiles of the measurements recorded. The red horizontal line near the top of some plots indicates the NAAQS for that pollution measure. Avg, Average; Max, maximum.
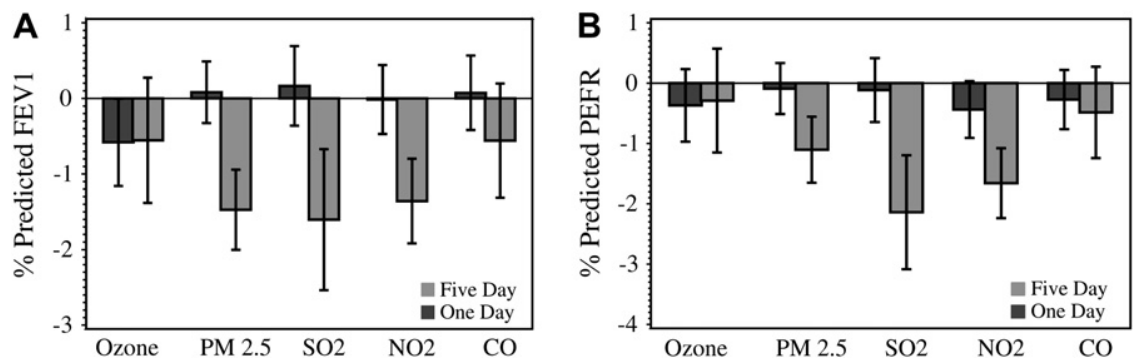

FIG 2. Estimated effect $(95 \% \mathrm{Cl})$ on pulmonary function of a 10 th to 90 th percentile increment in pollutant level in single-pollutant models among 937 inner-city children with asthma. The estimates shown are from models that included either a 1-day or 5-day average of pollutant concentration as the independent exposure variable. Adjusted for site, month, site-by-month interaction, temperature, and intervention group in mixed models. A, Percent predicted $\mathrm{FEV}_{1}$ as outcome variable. B, Percent predicted PEFR as outcome variable.

effects of inhaled pollutants on the lower airways require exposure longer than a single day.

Previous studies of the effects of air pollution on the health of inner-city children with asthma revealed associations of some pollutants with respiratory symptoms but less consistent associations with lung function. A panel study of 846 urban children with asthma in the Northeast and Midwest United States ${ }^{19}$ revealed that the morning PEFR was reduced and symptoms were increased in association with increased $\mathrm{O}_{3}$, but PEFR was not related to $\mathrm{SO}_{2}$ or $\mathrm{NO}_{2}$. In a panel study of 71 children with asthma in Mexico City, where ambient levels of PM10 and $\mathrm{O}_{3}$ exceeded those in our study, PEFR and respiratory symptoms were associated with the concentrations of both pollutants. ${ }^{21}$ Among 22 Hispanic children with asthma in Los Angeles, the concentrations of $\mathrm{O}_{3}, \mathrm{NO}_{2}, \mathrm{SO}_{2}$, and PM10 were associated with symptoms but not with reductions in PEFR. ${ }^{28}$ Our study differs from previous studies in its use of year-round data on a large number of patients with asthma followed for 2 years; the availability of data on PM2.5 and 4 other criteria pollutants; and the measurement of daily $\mathrm{FEV}_{1}$, which is more sensitive to mild airflow limitation than PEFR.
We observed stronger associations between decrements in lung function and increments in $\mathrm{NO}_{2}$ and $\mathrm{SO}_{2}$, but a weaker association with $\mathrm{O}_{3}$ than in 1 previous study. ${ }^{19}$ We also observed a significant association between decrements in lung function and increments in PM2.5, which was not measured in the other studies of innercity children with asthma.

Our observation of greater associations of lung function with 5-day average than with 1-day average pollutant concentrations is consistent with previous reports. For example, a time-series study in the Atlanta area revealed that the association between air quality measurements and ambulatory visits related to pediatric asthma was strongest for the 3-day to 5-day lagged moving average air quality measurements. ${ }^{34}$ An earlier timeseries study in Utah Valley also found that using 5-day average pollution measurements led to the strongest associations of particulate air pollution levels with respiratory symptoms in children. $^{35}$

Some previous panel studies not focused on inner-city patients with asthma have evaluated the associations between ambient air PM2.5 and lung function and respiratory symptoms among 
TABLE III. Mean $(95 \% \mathrm{CI})$ change in pulmonary function parameter at the 90th percentile of pollutant concentration relative to the 10th percentile

\begin{tabular}{|c|c|c|c|}
\hline & $\begin{array}{l}\text { 10th to 90th percentile } \\
\text { change }\end{array}$ & $\begin{array}{l}\text { Estimated change in } \mathrm{FEV}_{1}, \% \\
\text { predicted }\end{array}$ & $\begin{array}{c}\text { Estimated change in PEFR, \% } \\
\text { predicted }\end{array}$ \\
\hline \multicolumn{4}{|c|}{ Single-pollutant models } \\
\hline $\mathrm{O}_{3}$ & $26.7 \mathrm{ppb}$ & $-0.55(-1.38,+0.27)$ & $-0.29(-1.15,+0.57)$ \\
\hline $\mathrm{SO}_{2}$ & $12.4 \mathrm{ppb}$ & $-1.60(-2.54,-0.67) \dagger$ & $-2.14(-3.08,-1.19) \dagger$ \\
\hline $\mathrm{NO}_{2}$ & $20.4 \mathrm{ppb}$ & $-1.36(-1.92,-0.80) \dagger$ & $-1.66(-2.24,-1.08) \dagger$ \\
\hline $\mathrm{CO}$ & $872.1 \mathrm{ppb}$ & $-0.56(-1.31,+0.20)$ & $-0.49(-1.24,+0.27)$ \\
\hline $\mathrm{PM} 2.5$ & $13.2 \mu \mathrm{g} / \mathrm{m}^{3}$ & $-0.73(-1.33,-0.12)^{*}$ & $-0.25(-0.88,+0.38)$ \\
\hline $\mathrm{NO}_{2}$ & $20.4 \mathrm{ppb}$ & $-1.09(-1.77,-0.41) \dagger$ & $-1.61(-2.32,-0.90) \dagger$ \\
\hline
\end{tabular}

Adjusted for site, month, site-by-month interaction, temperature, and intervention group in a mixed model. Independent variable is 5-day average pollutant concentration. * Significant at $P<.05$.

$\dagger$ significant at $P<.01$.

TABLE IV. Risk of asthma-related symptoms and missed school days at the 90th percentile of pollutant concentration relative to the 10th percentile

\begin{tabular}{|c|c|c|c|c|c|}
\hline & \multirow[b]{2}{*}{ 10th to 90th percentile change } & $\begin{array}{l}\text { Wheeze-cough, } \\
\text { days } / 2 \mathbf{~ w k}\end{array}$ & $\begin{array}{c}\text { Nighttime asthma, } \\
\text { nights } / 2 \text { wk }\end{array}$ & $\begin{array}{l}\text { Slow play, } \\
\text { days } / 2 \text { wk }\end{array}$ & \multirow{2}{*}{$\begin{array}{c}\text { Missed school, } \geq 1 \\
\text { vs } 0 \mathrm{~d} / 2 \mathrm{wk}\end{array}$} \\
\hline & & \multicolumn{3}{|c|}{ Pollution impact $(95 \% \mathrm{Cl}) \ddagger$} & \\
\hline $\mathrm{O}_{3}$ & $26.7 \mathrm{ppb}$ & $1.03(0.82,1.28)$ & $0.85(0.64,1.14)$ & $0.87(0.67,1.14)$ & $1.31(0.83,2.06)$ \\
\hline PM2.5 & $13.2 \mu \mathrm{g} / \mathrm{m}^{3}$ & $0.98(0.88,1.09)$ & $1.11(0.94,1.30)$ & $1.01(0.89,1.15)$ & $1.33(1.06,1.66)^{*}$ \\
\hline $\mathrm{SO}_{2}$ & $12.4 \mathrm{ppb}$ & $1.06(0.87,1.30)$ & $1.14(0.89,1.45)$ & $1.07(0.85,1.35)$ & $1.13(0.78,1.64)$ \\
\hline \multicolumn{6}{|c|}{ Three-pollutant model } \\
\hline $\mathrm{O}_{3}$ & $26.7 \mathrm{ppb}$ & $1.04(0.82,1.32)$ & $0.82(0.60,1.12)$ & $0.86(0.65,1.14)$ & $1.35(0.82,2.20)$ \\
\hline PM2.5 & $13.2 \mu \mathrm{g} / \mathrm{m}^{3}$ & $0.92(0.81,1.05)$ & $1.03(0.86,1.23)$ & $0.92(0.79,1.06)$ & $1.13(0.87,1.45)$ \\
\hline $\mathrm{NO}_{2}$ & $20.4 \mathrm{ppb}$ & $1.24(1.02,1.52)^{*}$ & $1.29(1.00,1.68)$ & $1.33(1.06,1.66)^{*}$ & $1.33(0.87,2.02)$ \\
\hline
\end{tabular}

* Significant at $P<.05$.

$\uparrow$ Significant at $P<.01$.

$\$$ Numbers given are coefficients from the negative binomial model and indicate the multiplicative effect per unit change. For example, 1.17 indicates that a pollution increase from the 10th to 90th percentile of the distribution would result in a $17 \%$ increase in symptom frequency. Covariates include site, month, site-by-month interaction, temperature, call number, and intervention group. Independent variable is the 19-day average pollutant concentration.

children with and without asthma. ${ }^{10,14,21-24}$ A systematic review ${ }^{20}$ calculated a pooled effect estimate based on 5 studies of the association between changes in PM2.5 and PEFR. This estimate ranged from -3.15 to $-7.20 \mathrm{~L} / \mathrm{min}$ change in PEFR per $50 \mathrm{ug} /$ $\mathrm{m}^{3}$ change in PM2.5, depending on the calculation method. Our estimate of a $1.1 \%$ predicted decrease in PEFR per $13.2 \mathrm{ug} / \mathrm{m}^{3}$ increase in PM2.5 equals a $-12.5 \mathrm{~L} / \mathrm{min}$ change in PEFR per $50 \mathrm{ug} /$ $\mathrm{m}^{3}$ change in PM2.5, assuming a predicted value for PEFR of 300 $\mathrm{L} / \mathrm{min}$ (approximate average for our sample at the midpoint of follow-up). Our larger effect estimate may reflect the susceptibility of our patients with persistent asthma and their inner-city settings, where motor vehicle exhaust may make a larger contribution to PM2.5 than in other locations. ${ }^{27}$

A previous study of children with asthma in Southern California $^{36}$ found that bronchitis symptoms were more closely associated with $\mathrm{NO}_{2}$ and particulate organic carbon, with both surrogates for motor vehicle exhaust, than with the other measured pollutants. Venn et $\mathrm{al}^{37}$ linked childhood wheezing to residence near a main road, and Hoek et $\mathrm{al}^{38}$ and Laden et $\mathrm{al}^{39}$ have associated excess mortality more closely with exposure to trafficrelated pollutants than to pollutants from other sources. Peters et $\mathrm{al}^{40}$ and Pekkanen et $\mathrm{al}^{13}$ linked ultrafine particles (diameters below $0.1 \mathrm{um}$ ) to respiratory symptoms. Those findings suggest that ambient air pollution derived from motor vehicle emissions may have injurious effects on the respiratory health of children with asthma, and that the active agents could include specific organics and/or the ultrafine particles that are emitted from internal combustion engines. In the absence of data on the composition of particles in the PM2.5 fraction, which varies with geographic region and season, we cannot determine with certainty the source of fine particles associated with pulmonary function decline in our study.

Although we observed associations between pollutant concentrations and respiratory health in single-pollutant and multipollutant models, causal inferences regarding individual pollutants are limited by 2 factors. First, there are significant intercorrelations among the levels of most of the pollutants examined. Second, a particular pollutant concentration may serve as a surrogate measure of other, unmeasured, and possibly more causal components of urban air pollution mixtures. For example, Sarnat et $\mathrm{al}^{41}$ reported that, in Baltimore, Md, the ambient concentrations of the gaseous criteria pollutants were unrelated to personal exposures but were significantly related to personal exposure to PM2.5, which, in inner cities, is the most spatially 
homogeneous of these monitored pollutants. Despite these limitations, the observed associations with $\mathrm{NO}_{2}$, which is derived mostly from motor vehicle exhaust, suggest that traffic-derived pollution was responsible for at least part of the observed associations between pollutant concentrations and health effects. Studies of indoor $\mathrm{NO}_{2}$ exposure derived from cooking and heating sources indicate that such exposure may worsen respiratory symptoms in children with asthma. ${ }^{42}$ A time-series study in Australia and New Zealand ${ }^{7}$ revealed that the outdoor $\mathrm{NO}_{2}$ concentration was associated with asthma hospitalizations, whereas other pollutants were not. Thus, outdoor $\mathrm{NO}_{2}$ exposure may adversely affect the health of children with asthma, although the $\mathrm{NO}_{2}$ concentration may simply be acting as a surrogate for 1 or more other components of motor vehicle emissions.

Our data demonstrate temporal associations of air pollution levels with lung function and, for $\mathrm{NO}_{2}$, asthma symptoms. A 3pollutant model estimates that an increase in $\mathrm{NO}_{2}$ of $20.4 \mathrm{ppb}$ was associated with a relative risk of days with wheeze or cough of 1.24 -that is, a $24 \%$ increase in the frequency of symptom days. This same increase in $\mathrm{NO}_{2}$ was associated in a 3-pollutant model with an average reduction in $\mathrm{FEV}_{1}$ of $1.09 \%$ of the predicted level. Although our study lacked statistical power to detect excess hospitalizations or emergency visits in relation to air pollution, many asthma-related school absences were reported. A 20.4-ppb increase in $\mathrm{NO}_{2}$ was associated with a $67 \%$ increase in the risk of asthma-related school absence in a single-pollutant model. In 3-pollutant models, the excess risk of school absence appeared to be partitioned among multiple pollutants and did not reach statistical significance for any single pollutant. These associations may reflect irritant-induced bronchial smooth muscle constriction and/or mucosal inflammation, alterations with the potential for chronic as well as acute health effects. In a cohort of children in Southern California, ${ }^{43}$ lung function growth over a period of 8 years was significantly reduced in relation to average exposure to $\mathrm{NO}_{2}$ and $\mathrm{PM} 2.5$. If the associations with lung function, symptoms, and school absences observed in our study reflect airway effects with the potential to influence growth, then these acute manifestations of asthma morbidity could be associated with long-term adverse consequences of pollution exposure.

Passive smoke exposure (48\% of homes) and inhaled corticosteroid use (12\% of subjects) are not likely to be related to daily outdoor pollution fluctuations and therefore would not be expected to confound the associations between outdoor pollutant concentrations and asthma morbidity. These exposures, however, have important effects on the bronchial mucosa and could potentially modify the respiratory effects of pollutants. We looked for, but observed no evidence of, such effect modification, although our power to detect such modification may have been limited, especially for inhaled corticosteroid use.

Strengths of our study include its large sample of children with asthma with 2 years of individual-level data, including $\mathrm{FEV}_{1}$, and the availability of PM2.5 data. The absence of personal and indoor air-pollutant exposure data may be interpreted as a limitation because it introduces additional exposure misclassification that would tend to reduce the effect estimates. However, the centralsite, outdoor air quality measurements used in this study reflect the current approach to the regulation of air pollution, and the health effects associated with these measurements are therefore of substantial public health importance. Furthermore, the outdoor concentrations of the criteria pollutants, especially PM2.5, are reasonably homogeneous within a given city on a given day. ${ }^{44}$
In addition, in the homes of our subjects, indoor levels of $\mathrm{NO}_{2}$ are significantly correlated with outdoor levels measured at central monitoring sites (data not shown), especially during months when windows are open. To the extent that exposure misclassification does occur as a result of reliance on central pollution monitors, such misclassification would bias associations to the null. Another potential limitation is that half of the children in our sample were included in a home-based environmental intervention, potentially altering responses to air pollution. Our models included adjustment for intervention group. It remains possible that the bedroom high-efficiency particle air filters provided to most intervention group children could have diminished to some degree the influence of airborne fine particles in this half of the sample; however, we observed no significant modification of associations by intervention group.

In conclusion, we observed associations between short-term increases in air pollutant concentrations and health outcomes including reduced pulmonary function, respiratory symptoms, and missed school days related to asthma among urban children with moderate-to-severe asthma. Although the observed associations cannot be attributed with certainty to individual pollutants, the associations with $\mathrm{NO}_{2}$ suggest that 1 or more components of motor vehicle emissions may be causing excess respiratory symptoms among this vulnerable population of children with asthma, and that air pollutant levels below the current NAAQS may cause adverse effects on the health of children with asthma. Given the high prevalence of asthma in urban communities, these findings have important implications for air quality regulation and urban transportation policy.

The ICAS was a collaboration of the following institutions and investigators (*principal investigators): Boston University School of Medicine, Boston, Mass: G. O'Connor,* S. Steinbach, A. Zapata, J. Casagrande, L. Schneider (Children's Hospital, Boston, Mass); Albert Einstein College of Medicine/ Jacobi Medical Center, Bronx, NY: E. Crain,* L. Bauman, Y. Senturia, D. Rosenstreich; Children's Memorial Hospital, Chicago, Ill: R. Evans III,* J. Pongracic, A. Sawyer, K. Koridek; University of Texas Southwestern Medical Center at Dallas, Tex: R. S. Gruchalla, * V. Gan, Y. Coyle, N. F. Gorham; Mount Sinai School of Medicine, New York, NY: M. Kattan,* C. Lamm, M. Lippmann, E. Luder, M. Chassin, G. Xanthos; University of Washington School of Medicine and Public Health, Seattle, Wash: J. Stout, * G. Shapiro, L. Liu, J. Koenig, M. Lasley, S. Randels, H. Powell; University of Arizona College of Medicine, Tucson, Ariz: W. Morgan,* P. Enright, J. Goodwin, T. Garcia (El Rio Health Clinic, Tucson, Ariz); Data Coordinating Center, Rho, Inc, Chapel Hill, NC: H. Mitchell, * M. Walter, C. Visness, H. Lynn, S. Hart, W. Tolbert, E. Nuebler; Department of Environmental Health Laboratory, Harvard School of Public Health, Boston, Mass: H. Burge, M. Muilenberg, D. Gold; Johns Hopkins Dermatology, Allergy and Clinical Immunology Reference Laboratory, Johns Hopkins University School of Medicine, Baltimore, Md: R. Hamilton; National Institute of Allergy and Infectious Diseases, Bethesda, Md: M. Plaut, E. Smartt, K. Adams (retired); National Institute of Environmental Health Sciences, Research Triangle Park, NC: G. Malindzak, P. Mastin.

We thank all of the families who participated in ICAS.

Clinical implications: Efforts to reduce air pollution in US cities are warranted to protect the health of children with asthma.

\section{REFERENCES}

1. Burnett RT, Brook J, Dann T, Delocla C, Philips O, Cakmak S, et al. Association between particulate- and gas-phase components of urban air pollution and daily mortality in eight Canadian cities. Inhal Toxicol 2000;12:15-39. 
2. Schwartz J, Dockery DW, Neas LM. Is daily mortality associated specifically with fine particles? J Air Waste Manage Assoc 1996;46:927-39.

3. Sheppard L, Levy D, Norris G, Larson TV, Koenig JQ. Effects of ambient air pollution on nonelderly asthma hospital admissions in Seattle, Washington, 19871994. Epidemiology 1999;10:23-30.

4. US Environmental Protection Agency. Air quality criteria for particulate matter EPA/600/P-99/002aF. Research Triangle Park (NC): National Center for Environmental Assessment-RTP Office; 2004.

5. Norris G, YoungPong SN, Koenig JQ, Larson TV, Sheppard L, Stout JW. An association between fine particles and asthma emergency department visits for children in Seattle. Environ Health Perspect 1999;107:489-93.

6. White MC, Etzel RA, Wilcox WD, Lloyd C. Exacerbations of childhood asthma and ozone pollution in Atlanta. Environ Res 1994;65:56-68.

7. Barnett AG, Williams GM, Schwartz J, Neller AH, Best TL, Petroeschevsky AL, et al. Air pollution and child respiratory health: a case-crossover study in Australia and New Zealand. Am J Respir Crit Care Med 2005;171:1272-8.

8. Phalen RF. The particulate air pollution controversy: a case study and lessons Learned. Boston: Kluwer; 2002

9. Neas LM, Dockery DW, Koutrakis P, Tollerud DJ, Speizer FE. The association of ambient air-pollution with twice-daily peak expiratory flow-rate measurements in children. Am J Epidemiol 1995;141:111-22.

10. Schwartz J, Neas LM. Fine particles are more strongly associated than coarse particles with acute respiratory health effects in schoolchildren. Epidemiology 2000; 11:6-10.

11. Spektor DM, Lippmann M, Lioy PJ, Thurston GD, Citak K, James DJ, et al. Effects of ambient ozone on respiratory function in active, normal children. Am Rev Respir Dis 1988;137:313-20.

12. Delfino RJ, Zeiger RS, Seltzer JM, Street DH. Symptoms in pediatric asthmatics and air pollution: differences in effects by symptom severity, anti-inflammatory medication use and particulate averaging time. Environ Health Perspect 1998; 106:751-61

13. Pekkanen J, Timonen KL, Ruuskanen J, Reponen A, Mirme A. Effects of ultrafine and fine particles in urban air on peak expiratory flow among children with asthmatic symptoms. Environ Res 1997;74:24-33.

14. Peters A, Dockery DW, Heinrich J, Wichmann HE. Short-term effects of particulate air pollution on respiratory morbidity in asthmatic children. Eur Respir J 1997; 10:872-9.

15. Tiittanen P, Timonen KL, Ruuskanen J, Mirme A, Pekkanen J. Fine particulate ai pollution, resuspended road dust and respiratory health among symptomatic children. Eur Respir J 1999;13:266-73.

16. Friedman MS, Powell KE, Hutwagner L, Graham LM, Teague WG. Impact of changes in transportation and commuting behaviors during the 1996 Summer Olympic Games in Atlanta on air quality and childhood asthma. JAMA 2001; 285:897-905.

17. Ostro B, Lipsett M, Mann J, Braxton-Owens H, White M. Air pollution and exacerbation of asthma in African-American children in Los Angeles. Epidemiology 2001;12:200-8.

18. Thurston GD, Lippmann M, Scott MB, Fine JM. Summertime haze air pollution and children with asthma. Am J Respir Crit Care Med 1997;155:654-60.

19. Mortimer KM, Neas LM, Dockery DW, Redline S, Tager IB. The effect of air pollution on inner-city children with asthma. Eur Respir J 2002;19:699-705.

20. Ward DJ, Ayres JG. Particulate air pollution and panel studies in children: a systematic review. Occup Environ Med 2004;61:e13.

21. Romieu I, Meneses F, Ruiz S, Sienra JJ, Huerta J, White MC, et al. Effects of air pollution on the respiratory health of asthmatic children living in Mexico City. Am J Respir Crit Care Med 1996;154:300-7.

22. Neas LM, Dockery DW, Koutrakis P, Speizer FE. Fine particles and peak flow in children: acidity versus mass. Epidemiology 1999;10:550-3

23. Gold DR, Damokosh AI, Pope CA III, Dockery DW, McDonnell WF, Serrano P, et al. Particulate and ozone pollutant effects on the respiratory function of children in southwest Mexico City. Epidemiology 1999;10:8-16.
24. Ward DJ, Roberts KT, Jones N, Harrison RM, Ayres JG, Hussain S, et al. Effects of daily variation in outdoor particulates and ambient acid species in normal and asthmatic children. Thorax 2002;57:489-502.

25. Pope CA, Burnett RT, Thun MJ, Calle EE, Krewski D, Ito K, et al. Lung cancer, cardiopulmonary mortality, and long-term exposure to fine particulate air pollution. JAMA 2002;287:1132-41

26. Slaughter JC, Lumley T, Sheppard L, Koenig JQ, Shapiro GG. Effects of ambient air pollution on symptom severity and medication use in children with asthma. Ann Allergy Asthma Immunol 2003;91:346-53.

27. Krewski D, Rainham D. Ambient air pollution and population health: overview J Toxicol Environ Health A 2007;70:275-83.

28. Delfino RJ, Gong H, Linn WS, Pellizzari ED, Hu Y. Asthma symptoms in Hispanic children and daily ambient exposures to toxic and criteria air pollutants. Environ Health Perspect 2003;111:647-56.

29. Crain EF, Walter M, O'Connor GT, Mitchell H, Gruchalla RS, Kattan M, et al Home and allergic characteristics of children with asthma in seven U.S. urban communities and design of an environmental intervention: the Inner-City Asthma Study. Environ Health Perspect 2002;110:939-45

30. Morgan WJ, Crain EF, Gruchalla RS, O'Connor GT, Kattan M, Evans RI, et al. Results of a home-based environmental intervention among urban children with asthma. N Engl J Med 2004:351:1068-80.

31. Hsu KH, Jenkins DE, Hsi BP, Bourhofer E, Thompson V, Tanakawa N, et al. Ventilatory functions of normal children and young adults-Mexican-American, white, and black, I: spirometry. J Pediatr 1979;95:14-23.

32. US Environmental Protection Agency. Technology Transfer Network - Air Quality System. U.S.Environmental Protection Agency. Available at: http://www.epa.gov/ ttn/airs/airsaqs/. Accessed March 27, 2008.

33. Zanobetti A, Schwartz J, Dockery DW. Airborne particles are a risk factor for hospital admissions for heart and lung disease. Environ Health Perspect 2000;108:1071-7.

34. Sinclair AH, Tolsma D. Associations and lags between air pollution and acute respiratory visits in an ambulatory care setting: 25-month results from the aerosol research and inhalation epidemiological study. J Air Waste Manag Assoc 2004;54: 1212-8.

35. Pope CI, Dockery DW. Acute health effects of PM pollution on symptomatic and asymptomatic children. Am Rev Respir Dis 1992;145:1123-8.

36. McConnell R, Berhane K, Gilliland F, Molitor J, Thomas D, Lurmann F, et al. Prospective study of air pollution and bronchitic symptoms in children with asthma Am J Respir Crit Care Med 2003;168:790-7.

37. Venn AJ, Lewis SA, Cooper M, Hubbard R, Britton J. Living near a main road and the risk of wheezing illness in children. Am J Respir Crit Care Med 2001;164:2177-80.

38. Hoek G, Brunekreef B, Goldbohm S, Fischer P, van den Brandt PA. Association between mortality and indicators of traffic-related air pollution in the Netherlands: a cohort study. Lancet 2002;360:1203-9.

39. Laden F, Neas LM, Dockery DW, Schwartz J. Association of fine particulate matter from different sources with daily mortality in six US cities. Environ Health Perspect 2000;108:941-7.

40. Peters A, Wichmann HE, Tuch T, Heinrich J, Heyder J. Respiratory effects are associated with the number of ultrafine particles. Am J Respir Crit Care Med 1997, 155:1376-83.

41. Sarnat JA, Koutrakis P, Suh HH. Assessing the relationship between personal particulate and gaseous exposures of senior citizens living in Baltimore, MD. J Air Waste Manage Assoc 2000;50:1184-98.

42. Belanger K, Gent JF, Triche EW, Bracken MB, Leaderer BP. Association of indoor nitrogen dioxide exposure with respiratory symptoms in children with asthma. Am J Respir Crit Care Med 2006;173:297-303.

43. Gauderman WJ, Avol E, Gilliland F, Vora H, Thomas D, Berhane K, et al. The ef fect of air pollution on lung development from 10 to 18 years of age. $\mathrm{N}$ Engl J Med 2004;351:1057-67.

44. Ito K, DeLeon S, Thurston G, Nadas A, Lippmann M. Monitor to monitor temporal correlation of air pollution in the contiguous US. J Expos Anal Environ Epidemiol $2005 ; 15: 173-84$. 


\section{METHODS}

\section{Sample}

In conjunction with ICAS, ${ }^{\mathrm{E} 1, \mathrm{E} 2}$ we conducted an observational panel study of the respiratory health effects of air pollution. The objective of ICAS was to determine whether a home-based environmental intervention tailored to each child's sensitization and environmental risk profile could reduce the symptoms of asthma and decrease the use of health care services. Simultaneously, using a 2-by-2 factorial design, ICAS evaluated a physician-feedback intervention that included bimonthly reports of the children's asthma symptoms and use of health care services to their primary care physicians. ${ }^{\mathrm{E} 3}$ The ICAS cohort included 937 children with persistent asthma. They were 5 to 12 years old, had a positive allergy skin test result to at least 1 indoor allergen, lived in low-income census tracts in Boston, the Bronx, Chicago, Dallas, New York, Seattle, and Tucson, and were followed for 24 months as part of the ICAS protocol. Subject recruitment took place throughout a full 12-month period, such that the monitoring of health and pollution data, as described, was staggered throughout the calendar year. For the current study, we excluded from the Seattle area cohort 53 children that lived in Tacoma because of a lack of nearby US Environmental Protection Agency monitoring stations with sufficiently complete data collection. Of the remaining 884 children, 23 from other sites were excluded because of insufficient pulmonary function data, and 861 children were included in the analysis.

\section{Health data}

Every 6 months, children performed twice-daily measurements of PEFR and $\mathrm{FEV}_{1}$ for 2 weeks using an electronic spirometer that recorded the date and time of each measurement. At the beginning of each 2-week period, children were instructed how to perform spirometry and were asked to perform 14 consecutive days of morning and evening forced expiratory maneuvers. The electronic spirometer coached the subjects through 3 maneuvers in the morning and again in the evening, then stored the highest $\mathrm{FEV}_{1}$ and the highest PEF from these 3 maneuvers. From the recorded data, percent predicted values were calculated by using published regression equations ${ }^{\mathrm{E} 4}$ that include parameters for race and ethnicity (black, white, Hispanic), sex, and height.

Caretaker-reported asthma symptom data were collected by telephone interviews every 2 months for the full 2 -year follow-up period. In each telephone interview, caretakers were asked to recall the number of days in the past 2 weeks that the child experienced wheezing or coughing, was awakened at night by asthma symptoms, experienced slower than normal play or activity because of asthma symptoms, and missed school because of asthma symptoms. The specific days on which symptoms had occurred were not queried.

\section{Pollution measurements}

Daily measurements of the ambient air concentrations of PM2.5, $\mathrm{NO}_{2}, \mathrm{SO}_{2}$, $\mathrm{CO}$, and $\mathrm{O}_{3}$ (average of hourly measurements), were obtained from the US Environmental Protection Agency Aerometric Information Retrieval System database. ${ }^{\mathrm{E} 5}$ Within each community, we used data from all available monitoring sites that were located in reasonable proximity to the homes of the study population, that had reasonably complete pollution data during the study period, and that were not located at an industrial pollution source that would make measurements meaningless in terms of community exposure. In most cases, subjects' homes were fairly tightly clustered; the median distance to the nearest monitoring station was $2.3 \mathrm{~km}$. For each monitoring site, we used all available pollution data; if more than 1 monitoring site within a city was used, their readings were combined using the method of Zanobetti et al. ${ }^{\mathrm{E} 6}$

\section{Data analysis}

The relationships between $\mathrm{FEV}_{1}$ and PEFR and the pollutant concentrations were assessed by using mixed-effects models, in which each day's $\mathrm{FEV}_{1}$ or PEFR, expressed as a percentage of predicted, was used as the dependent variable, and the independent variables included pollutant concentrations (the mean of the 1 or more days preceding the day of the pulmonary function measurement), city, month (to adjust for seasonal effects), a city-by-month interaction term, a piecewise linear spline for the mean temperature on the day of the pulmonary function measurement (knot points at $42.7^{\circ} \mathrm{F}$ and $72.6^{\circ} \mathrm{F}$ ), whether it was obtained in the morning or evening, and the ICAS intervention group. This mixed modeling approach assesses variation of health outcomes with pollution level both within individuals and between individuals. The models let individuals have their own individual intercept of the outcome-exposure relationship, thereby adjusting for differences in the baseline lung function of individuals. Similar to other time-series investigations of the acute effects of air pollution on respiratory health, we examined alternative pollution concentration moving averages from 1 to 7 days as well as undistributed lag models. We observed that a 5-day moving average pollution concentration provided the most consistent significant associations with lung function effects, and we therefore used 5-day averages for the main analyses presented. To be included in the analysis, lung function measurements on a given day needed to be associated with nonmissing pollution data on at least 4 of the previous 5 days. When pollution data were missing for 1 of the 5 days, the 4-day average was used in place of the 5-day average.

Single-pollutant models were used to examine the relationship of lung function to 1 pollutant at a time. A 3-pollutant model including $\mathrm{NO}_{2}, \mathrm{O}_{3}$, and PM2.5 was used to evaluate the independent relationship of lung function to the concentration of each of these pollutants while adjusting for the associations with the other 2 pollutants. We chose these 3 pollutants for the multipollutant model because of their known health effects and because the daily $\mathrm{O}_{3}$ and PM2.5 concentrations are not correlated in the exposure data used in this study (as described in Results).

The relationships of 2-week recall symptoms to pollutant measurements were assessed by using generalized estimating equation models, with a negative binomial distribution for count outcomes and a binomial distribution for the occurrence of 1 or more asthma-related school absence. The frequency of each symptom or the occurrence of 1 or more school absence during the 2week recall period was the dependent variable, and the independent pollution variable was the mean concentration during the 19 days preceding the interview-that is, the 14 days of the symptom recall period plus a 5-day lag period preceding the symptom recall period. We chose this approach because of the finding that a 5-day moving average revealed the most consistent associations between pollution concentrations and lung function (as noted), suggesting that respiratory effects may be influenced by cumulative exposure over multiple days. The other independent variables were the same as in the lung function models. The effect estimates from the models for both pulmonary function and symptoms were scaled to a 10th to 90th percentile increase of the daily average pollutant concentrations across all 7 communities.

For all models, results are presented by contrasting symptoms or lung function at the 90th percentile of all measurements of a given pollutant to symptoms or lung function at the 10th percentile of measurements.

\section{REFERENCES}

E1. Crain EF, Walter M, O'Connor GT, Mitchell H, Gruchalla RS, Kattan M, et al. Home and allergic characteristics of children with asthma in seven U.S. urban communities and design of an environmental intervention: the Inner-City Asthma Study. Environ Health Perspect 2002;110:939-45.

E2. Morgan WJ, Crain EF, Gruchalla RS, O'Connor GT, Kattan M, Evans RI, et al. Results of a home-based environmental intervention among urban children with asthma. N Engl J Med 2004;351:1068-80.

E3. Kattan M, Crain EF, Steinbach S, Visness CM, Walter M, Stout JW, et al. A randomized clinical trial of clinician feedback to improve quality of care for innercity children with asthma. Pediatrics 2006;117:e1095-103.

E4. Hsu KH, Jenkins DE, Hsi BP, Bourhofer E, Thompson V, Tanakawa N, et al. Ventilatory functions of normal children and young adults: Mexican-American, white, and black, I: spirometry. J Pediatr 1979;95:14-23.

E5. US Environmental Protection Agency. Technology Transfer Network: Air Quality System. US Environmental Protection Agency. Available at: http://www.epa.gov/ ttn/airs/airsaqs/. Accessed March 27, 2008.

E6. Zanobetti A, Schwartz J, Dockery DW. Airborne particles are a risk factor for hospital admissions for heart and lung disease. Environ Health Perspect 2000; 108:1071-7. 